\title{
Tandem Mass Tag 10-plex
}

National Cancer Institute

\section{Source}

National Cancer Institute. Tandem Mass Tag 10-plex. NCI Thesaurus. Code C161869.

A tandem mass tag reagent preparation containing ten distinct isotope substitutions. 